\title{
Reishi Mushroom Attenuates Hepatic Inflammation and Fibrosis Induced by Irradiation Enhanced Carbon Tetrachloride in Rat Model
}

\author{
Omama E. El Shawi1, Sahar S. Abd El-Rahman 2*, Marwa Abd El Hameed ${ }^{3}$ \\ ${ }^{1}$ Health Radiation Research Department, National Centre for Radiation Research and Technology, Atomic \\ Energy Authority, Cairo, Egypt \\ ${ }^{2}$ Department of Pathology, College of Veterinary Medicine, Cairo University \\ ${ }^{3}$ Drug Radiation Research Department, National Centre for Radiation Research and Technology, \\ Atomic Energy Authority, Cairo, Egypt \\ Email: 'saharsamirmah@cu.edu.eg, saharsamirmah@hotmail.com
}

Received 11 August 2015; accepted 6 October 2015; published 9 October 2015

Copyright (C) 2015 by authors and Scientific Research Publishing Inc.

This work is licensed under the Creative Commons Attribution International License (CC BY).

http://creativecommons.org/licenses/by/4.0/

(c) (i) Open Access

\begin{abstract}
This work was undertaken to establish a new experimental model of hepatic fibrosis by gamma irradiation and $\mathrm{CCl}_{4}$ and to study the hepatoprotective effect of Reishi Mushroom (RM) against hepatic fibrosis induced in that model. Our results revealed that oral co-administration of 110 $\mathrm{mg} / \mathrm{kg} \mathrm{RM}$ by gavage to fibrotic rats offered an obvious hepatic protection as assured by the significant decrement in ALT and AST, HP content, MDA and NO levels with elevation of the antioxidant enzymes activities. The levels of TGF- $\beta$, TNF- $\alpha$, HO-1 and type-1 collagen and their m-RNA expression were markedly declined as compared with those of fibrotic rats. Microscopical examination revealed that the exposure of rats to radiation aggravated the effect of $\mathrm{CCl}_{4}$ causing extensive collagen deposition and marked pseudolobulation of the hepatic parenchyma indicative of bridging fibrosis. While, oral co-administration of RM obviously improved the state of steatosis and apparently suppressed hepatic fibrogenesis.
\end{abstract}

\section{Keywords}

Carbon Tetrachloride, Gamma Irradiation, Hepatic Fibrosis, Reishi Mushroom, Rats

\footnotetext{
${ }^{*}$ Corresponding author.
}

How to cite this paper: El Shawi, O.E., El-Rahman, S.S.A. and El Hameed, M.A. (2015) Reishi Mushroom Attenuates Hepatic Inflammation and Fibrosis Induced by Irradiation Enhanced Carbon Tetrachloride in Rat Model. Journal of Biosciences and Medicines, 3, 24-38. http://dx.doi.org/10.4236/jbm.2015.310004 


\section{Introduction}

Liver is the key organ of metabolism and excretion of many substances; hence it is often exposed to variety of xenobiotics and therapeutic agents. Hepatic fibrosis induced by chronic liver injuries as a result of hepatitis viruses, chronic alcohol intake, lipidperoxidative products and various drugs could end by cirrhosis [1]. Chronic liver diseases are usually associated with inflammatory reaction that is considered a key contributor of hepatocellular damage with a resultant progression to liver fibrosis and may be to hepatocellular carcinoma [2].

Radiation-induced liver disease is mainly due to oxidative damage, leading to liver inflammation and fibrosis [3].

$\mathrm{CCl}_{4}$ has been widely reported to induce acute and chronic tissue injuries. A single dose of $\mathrm{CCl}_{4}$ can result in centrizonal necrosis and steatosis [4]. While, prolonged administration of $\mathrm{CCl}_{4}$ can cause hepatic fibrosis caused by its highly active metabolite trichloromethyl $\left(\mathrm{CCl}_{3}\right)$ that is produced by Cytochrome p450 during $\mathrm{CCl}_{4}$ metabolism in hepatocytes [5]. Those trichloromethyl radicals are known to trigger a cascade of events that result in hepatic inflammation and fibrosis [6] through activation of hepatic stellate cells (HSCs) [7]. Marked changes in the extracellular matrix (ECM) take place as hepatic fibrogenesis progresses with more expression of type-1 collagen which is the most abundant ECM protein in hepatic fibrosis [8]. The activation of HSCs is mediated by reactive oxygen species and various cytokines, including transforming growth factor (TGF)- $\beta$, tumor necrosis factor (TNF)- $\alpha$ [9] and interleukin-6 (IL-6), which are able to stimulate collagen synthesis [10].

Mushroom is widely used everywhere all over the world as an important source of nutrition and therapy [11]. Reishi Mushroom (RM), also known as Ganoderma lucidum (GL) is a traditional oriental medicinal mushroom. Its role in the treatment of chronic hepatopathy with little or no side effects is widely known [12]. Generally, many constituents in Mushrooms are known to have varieties of biological activities including antioxidant [13], antiinflammatory [14] and hepatoprotective properties [15]. Furthermore, a protective action of water or ethanol extracts of $G$. lucidum against acute hepatitis in rats and mice have been recorded [16]. In addition, among many constituents present in G. lucidum, triterpenoids and polysaccharides have proved to inhibit hepatitis and liver fibrosis [17] [18].

Aim of work: The main objective of the present study was to establish a fibrosis model using gamma irradiation and $\mathrm{CCl}_{4}$ and to demonstrate the protective effect of $\mathrm{RM}$ aqueous solution against the induced hepatic fibrosis with focusing on the precise cellular and molecular mechanisms.

\section{Materials and Methods}

\subsection{Chemicals}

$\mathrm{CCl}_{4}$ (C25630) was obtained from Sigma Chemical Co. (St. Louis, MO) USA. The kits used were purchased from Bio-diagnostic, Cairo, Egypt. Reishi Mushroom (RM) powder was provided by DXN marketing SD.BHD (283904-P), Malaysia.

\subsection{Animals}

Fifty-five male albino rats with an average weight of 145 - 160 gm were obtained from the animal house belonging to Research Institute of Ophthalmology, Giza, Egypt. Rats were housed in regular designed cages and maintained in good ventilation, at a temperature of $25^{\circ} \mathrm{C} \pm 5^{\circ} \mathrm{C}, 60 \%$ humidity, with suitable illumination conditions (light/dark cycle) and were allowed standard pellet diet and fresh water ad libitum. Animals were left one week for acclimatization on lab environment before starting the onset of the experiment. Animal care and the protocol of animal treatment were approved by the Animal Care Committee of the National Centre for Radiation Research and Technology (NCRRT), Cairo, Egypt, and in accordance with the recommendations of the proper care and use of laboratory animals.

\subsection{Irradiation Facilities}

Irradiation was performed through the use of a Canadian Gamma Cell-40 $\left({ }^{137} \mathrm{Cs}\right)$ at the National Centre for Radiation Research and Technology (NCRRT), Cairo, Egypt. The dose rate was 0.675 Gy/minute.

\subsection{Induction Models of Liver Fibrosis in Rats}

Two models of hepatic fibrosis were established in the current study. The $1^{\text {st }}$ model was established using $\mathrm{CCl}_{4}$ 
alone as; $\mathrm{CCl}_{4}$ in olive oil ( $\left.50 \% \mathrm{~V} / \mathrm{V}\right)$ at a dose of $2 \mathrm{ml} / \mathrm{Kg}$ body weight was delivered subcutaneously three times/ week for six weeks. While in the $2^{\text {nd }}$ model, gamma irradiation was used to promote and enhance the $\mathrm{CCl}_{4}$ induced hepatic fibrosis. Rats were exposed to six fractions (each of $2 \mathrm{~Gy}$ ) of gamma irradiation once/week up to cumulative dose of $12 \mathrm{~Gy}$ concurrently with $\mathrm{CCl}_{4}$ as in the $1^{\text {st }}$ model.

\subsection{Experimental Design}

Rats were randomly divided into five groups. Group (Gp) 1; control rats were s/c injected with the vehicle olive oil $(0.2 \mathrm{ml}) . \mathrm{Gp} 2$; rats in this group were treated with $\mathrm{RM}$ aqueous solution $(1100 \mathrm{mg} / \mathrm{kg})$ by gavage three times/ week. Gp3; represented the $1^{\text {st }}$ model of fibrosis; rats were subcutaneously injected with $\mathrm{CCl}_{4}$ in olive oil (2 $\mathrm{ml} / \mathrm{kg}$ )3 times/week for six weeks. Gp4; represented the $2^{\text {nd }}$ model of fibrosis; rats of this group were subjected to gamma irradiation and $\mathrm{CCl}_{4}$ as described previously. Gp5; $\left(\mathrm{RM}+\mathrm{IRR}+\mathrm{CCl}_{4}\right.$ treated group) rats were treated with $\mathrm{RM}$ as in group 2 and were exposed to both IRR $+\mathrm{CCl}_{4}$ as in group 4 . The time interval between $\mathrm{CCl}_{4}$ injection and RM administration was taken into account to be at least 5 hours to avoid the interference of the metabolic substances. Carful observation was carried out for all animals along the experimental period and body weights were recorded weekly. At the end of the experimental period, rats were sacrificed under gentle diethyl ether anesthesia prior to which blood samples were collected into heparinized test tubes for plasma separation for biochemical analysis. Through PM examination was carried out and livers were dissected out, washed with saline, dried on a filter paper and weighted. Each liver was divided into two parts; one was fixed in $10 \%$ buffered neutral formalin for histopathological examination while the second part was kept at $-20^{\circ} \mathrm{C}$ till used for biochemical analysis.

\subsection{Biochemical Parameters Investigated in Blood Plasma}

ALT and AST activities, total Protein (TP) and albumin (Alb) in plasma were determined using the available commercial kits purchased from Bio-Diagnostic Co., Cairo, Egypt. Plasma TGF- $\beta$ and TNF- $\alpha$ were measured by ELISA kit immunoassay supplied by R \& D Quantikine USA (Catalog Number: RTA00, MB100B) according to manufacturer's instructions.

\subsection{Biochemical Parameters Investigated in Liver Homogenate}

\subsubsection{Hydroxyproline (HP) Assay}

HP; an indicator for hepatic collagen amount was colorimetriclly assayed in liver tissue homogenate as previously described [19].

\subsubsection{Evaluation of Antioxidant Status in Hepatic Tissue}

Malondiladehyde (MDA); the end product of lipid peroxidation [20], nitric oxide (NO) [21], glutathione (GSH) content [22], the activities of super oxide dismutase (SOD) [23] and catalase (CAT) [24] were assayed in the hepatic tissue homogenates of rats of all groups.

\subsubsection{Heme 0xygenase-1 (H0-1) Activity Assay}

Liver tissues were homogenized with 2.5 volume Tris-HCl buffer $(10 \mathrm{~m} \mathrm{~mol} / \mathrm{L}, \mathrm{pH} 7.6)$ containing $250 \mathrm{mmol} / \mathrm{L}$ sucrose and $0.4 \mathrm{mmol} / \mathrm{L}$ phenyl methylsulfonyl fluoride. The homogenates were centrifuged at $800 \mathrm{~g}$ for $10 \mathrm{mi}-$ nutes and then centrifuged at $13.500 \mathrm{~g}$ for 20 minutes to produce the mitochondrial pellet. The supernatant was withdrawn. The protein content in liver homogenate was determined [25]. The activity of HO-1 in the supernatant was determined as previously described [26]. Billirubin formed was determined by calculation of the difference in absorbance between $464 \mathrm{~nm}$ and $530 \mathrm{~nm}$. The HO-1 activity was expressed as picomoles of billirubin per milligram of protein per hour using standard billirubin curve.

\subsubsection{RNA Extraction and RT-PCR Analysis for TGF- $\beta 1$, TNF- $\alpha$, HO-1 and Type- 1 Collagen}

Total RNA was isolated from liver tissue homogenate using RN easy Purification Reagent (Qiagen, Valencia, Callifornia) according to the manufacturer's protocol. Extracted RNA was quantified by spectrophotometer at 260 $\mathrm{nm}$. Reverse transcription was carried out on $5 \mu \mathrm{g}$ RNA from each liver sample using MMuLV reverse transcriptase in a $50 \mu \mathrm{L}$ reaction volume. Mixtures of the reverse transcription were used for amplification of fragments specific forTGF- $\beta 1$, TNF- $\alpha$, HO- 1 and Type- 1 collagen by PCR using the primer pairs listed in Table 1. 
Table 1. Primer sequences used for real time PCR.

\begin{tabular}{cc}
\hline primer & \multicolumn{1}{c}{ sequence } \\
\hline TGF- $\beta 1$ & Forward primer: 5'-AGGGCTACCATGCCACTTC-3' \\
& Reverse primer: 5'-GCGGCACGCAGCACGGTGAT-3' \\
TNF- $\alpha$ & Forward primer: 5'-GAAAAGCAAGCAGCCAACCA-3' \\
& Reverse primer: 5'-CGGATCATGCTTTCTGTGCTC-3' \\
HO-1 & Forward primer: 5'-TTTCAAAGGGTCAGGTGTC-3' \\
& Reverse primer: 5'-CCTTCTGCGGCAATCTTCTTC-3' \\
Type-1 collagen & Forward primer: 5'-AATTGGAGCTGTTGGTAACGC-3' \\
& Reverse primer: 5'-CACCAGTAAGGCCGTTTGC-3' \\
GADPH & Forward primer: 5'-CTCCCATTCTTCCACCTTTG-3' \\
& Reverse primer: 5'-CTTGCTCTCAGTATCCTTGC-3' \\
\hline
\end{tabular}

The levels of expression of all transcripts were normalized to that of glyceraldehyde-3-phosphate dehydrogenase (GAPDH) mRNA in the same tissue sample. The real time PCR was performed using the QuantiTect SYBR green PCR Kit (Qiagen, Germany) according to the manufacturer's instructions, by Applied Biosystems 7500 Instrument, USA. The PCR reaction mix was carried out in a total volume of $25 \mu \mathrm{L}$, containing $2 \times$ QuantiTect SYBR green PCR master mix, $20 \mathrm{pmol} / \mu \mathrm{L}$ specific primer. Subsequently, cDNA was synthesized from purified RNA. The protocol consisted of 45 amplification cycles, each conducted as follows; 10 min at $95^{\circ} \mathrm{C}$ (holding stage), 15 sec for denaturation at $95^{\circ} \mathrm{C}$, $30 \mathrm{sec}$ for annealing at $60^{\circ} \mathrm{C}$ and another $15 \mathrm{sec}$ for elongation at $60^{\circ} \mathrm{C}$. RT-PCR was carried out as has been described previously [27].

\subsection{Histopathological Studies}

Formalin fixed liver specimens were routinely processed using conventional paraffin embedding technique. Paraffin blocks were serially sectioned at 4 - 5 um thickness and stained with H \& E [28]. Azan stain was used to demonstrate collagen fibers and the progress of fibrosis [28].

\subsection{Immunohistochemistry}

Labeled streptoavidin-biotin method was used for immunohistochemical detection of $\alpha$-SMA using a Histostatinplus bulk kit (Zymed Laboratories Ins., San Francisco, CA, USA). The primary antibody used was mononuclonal anti-smooth muscle actin, at a dilution of 1:800 (clone 1A4, Sigma Co., St. Lois, MO, USA).

\subsection{Statistical Analysis}

Data were analyzed using SPSS Version 20.0. Differences between experimental groups were analyzed using one-way analysis of variance. All differences were considered statistically significant at $P<0.05$.

\section{Results}

\subsection{Clinical and Postmortem Examination}

Rats of $\mathrm{CCl}_{4}$ and IRR $+\mathrm{CCl}_{4}$ treated groups appeared depressed with lusterless fur and decreased appetite. Livers of rats of $\mathrm{CCl}_{4}$ were swollen with rounded borders, irregular surface and fatty appearance. While that of IRR $+\mathrm{CCl}_{4}$ treated rats were severely distorted with fatty appearance.

\subsection{The Effect of RM on Body Weight and Liver Weight Index of Fibrotic Rats}

As shown in Table 2, a significant $(P<0.001)$ decrease in body weight gain coupled with significant increase $(P$ $<0.001)$ in liver weight index was observed in both models of fibrosis generated in this study as compared to the control set. Moreover, more pronounced changes in body weight $(P<0.001)$ and in liver index $(P<0.01)$ were noticed in IRR $+\mathrm{CCl}_{4}$ treated rats than in those treated with the sole $\mathrm{CCl}_{4}$ alone. On contrary, RM co-administration to IRR $+\mathrm{CCl}_{4}$ treated rats caused significant restoration $(P<0.001)$ in body weight gain and liver weight index near to the normal values $(P>0.05)$. 
Table 2. The effect of Reishi Mushroom (RM) on body weight and liver weight index in fibrotic rats.

\begin{tabular}{cccc}
\hline \multirow{2}{*}{ Treatments } & \multicolumn{2}{c}{ Body Weight (g) } & Liver Index (\%) \\
\cline { 2 - 3 } $\mathbf{C T}$ & Initial & Final & $2.48 \pm 0.19$ \\
$\mathbf{R M}$ & $154.4 \pm 2.4$ & $268.4 \pm 3.5$ & $2.78 \pm 0.02$ \\
$\mathbf{C C l}$ & $154.8 \pm 3.8$ & $244.1 \pm 6.8^{*}$ & $3.9 \pm 0.21^{* * *}$ \\
$\mathbf{I R R}+\mathbf{C C l}_{\mathbf{4}}$ & $145.6 \pm 1.8$ & $242.3 \pm 4.7^{* *}$ & $4.76 \pm 0.12^{* * *, \# \#}$ \\
$\mathbf{R M}+\mathbf{I R R}+\mathbf{C C l}_{4}$ & $144.7 \pm 1.3^{\mathrm{NS}}$ & $218.8 \pm 5.7^{* * *, \mathrm{a}}$ & $3.48 \pm 0.11^{\sharp}$ \\
\hline
\end{tabular}

Each value represents the mean $\pm \mathrm{SE}$ of 5 variables/group. Significant difference versus corresponding $\mathrm{CT}$ group at ${ }^{* * *} P<0.001,{ }^{* *} P<0.01,{ }^{*} P<0.05$. Significance change of $\mathrm{CCl}_{4}$ from IRR $+\mathrm{CCL}_{4}$ at ${ }^{\#} P<0.05$, ${ }^{\#} P<0.01$. Significant difference of Gp5 $\left(\mathrm{RM}+\mathrm{IRR}+\mathrm{CCl}_{4}\right)$ from IRR $+\mathrm{CCl}_{4}$ at ${ }^{\sharp} P<0.001$.

\subsection{Effect of RM on ALT and AST Activities, TP, Alb, TNF- $\alpha$ and TGF- $\beta$ Levels of Fibrotic Rats}

It was observed that; RM treated rats did not show any significant $(P>0.05)$ changes of any of the investigated parameters in their blood plasma as well as in hepatic tissue compared to those of control rats.

A significant $(P<0.001)$ elevation in ALT and AST activities, TNF- $\alpha$ and TGF- $\beta$ with a significant $(P<0.001)$ reduction in plasma TP and Alb concentration was noticed in plasma of $\mathrm{CCl}_{4}$ and $\mathrm{IRR}+\mathrm{CCl}_{4}$ treated groups when compared with controls (Figures 1-3). The highly significant $(P<0.05)$ changes were noticed in IRR $+\mathrm{CCl}_{4}$ treated rats compared with those of the sole $\mathrm{CCl}_{4}$ treatment. On contrary, the administration of RM to IRR $+\mathrm{CCl}_{4}$ treated rats resulted in significant $(P<0.001)$ improvement of all of the above altered parameters compared to those of model 2 rats.

\subsection{Effect of RM on Hydroxyproline Content in Liver Homogenate of Fibrotic Rats}

Hydroxyproline content was significantly $(P<0.001)$ increased following $\mathrm{CCl}_{4}$ treatment and showed higher significant $(P<0.01)$ increase following IRR $+\mathrm{CCl}_{4}$ treatment than its level in model 1 . By contrast, oral administration of RM with IRR $+\mathrm{CCl}_{4}$ significantly restored the hepatic hydroxyproline content compared with its level in model 2 rats (Figure 4).

\subsection{Effect of RM on Antioxidant Status in Hepatic Tissue of Fibrotic Rats}

Data in (Figure 5 and Figure 6) revealed significant $(P<0.001)$ elevation in MDA and NO levels accompanied with significant $(P<0.001)$ decrease in GHS content and SOD and CAT activities in liver homogenates of $\mathrm{CCl}_{4}$ as well as IRR $+\mathrm{CCl}_{4}$ treated rats. Nevertheless, the changes in the antioxidant markers were higher in IRR + $\mathrm{CCl}_{4}$ treated group $(P<0.01)$ compared to the corresponding values in $\mathrm{CCl}_{4}$ alone treated rats. Oral administration of RM significantly restored the altered levels of the investigated antioxidants in hepatic tissue of Gp5 rats compared with Gp4.

\subsection{Effect of RM on Heme 0xygenase-1 (HO-1) Activity in Hepatic Tissue of Fibrotic Rats}

The activity of HO-1 in hepatic tissue was significantly increased in the two models $(P<0.001)$. A highly significant increase in HO-1 activity was recorded in the $2^{\text {nd }}$ model in comparison with the $1^{\text {st }}$ one. Concurrent administration of RM along with IRR $+\mathrm{CCl}_{4}$ could significantly $(P<0.05)$ reduced the HO-1 activity as compared to IRR+ $\mathrm{CCl}_{4}$ treated rats (Figure 6).

\subsection{Effect of RM on the mRNA Levels of TGF- $\beta$, TNF- $\alpha$, HO-1, and Type- 1 Collagen in Hepatic Tissue of Fibrotic Rats}

As shown in (Figure 7(A) and Figure 7(B)) the mRNA levels of TGF- $\beta$, TNF- $\alpha$, HO-1 and type- 1 collagen were significantly $(P<0.001)$ increased in the two rats' models as compared with control set, with a more conspicuous $(P<0.001)$ increase in their mRNA expression in the $2^{\text {nd }}$ model when compared to the $1^{\text {st }}$ model. 


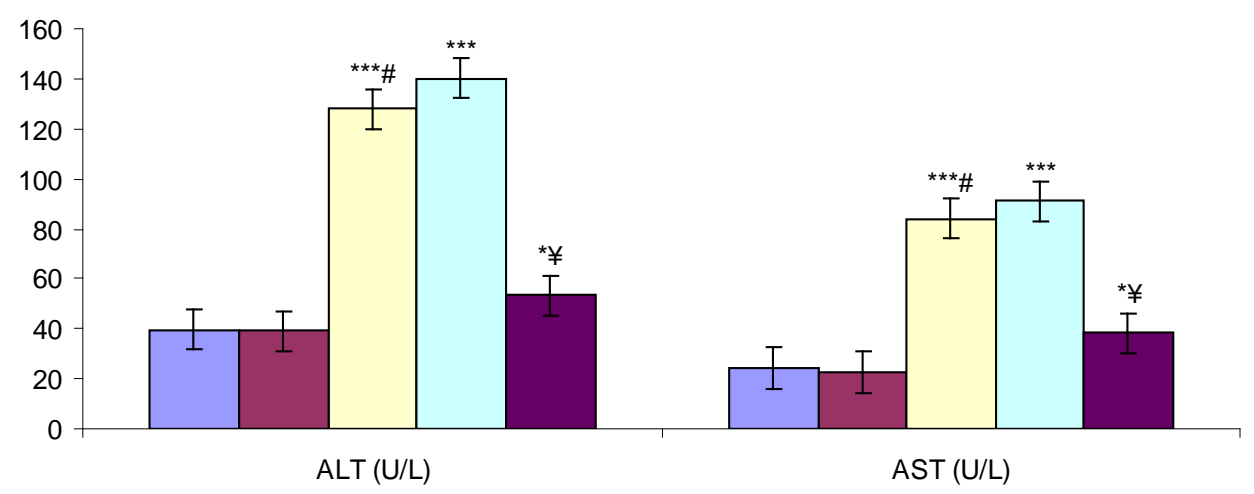

Figure 1. Effect of RM on ALT and AST activities in fibrogenic rats. Each value represents the mean \pm SE. Significant difference versus corresponding control group at ${ }^{* * *} P<0.001$. Significant difference of IRR $+\mathrm{CCL}_{4}$ versus corresponding $\mathrm{CCL}_{4}$ group at ${ }^{\#} P<0.05$, ${ }^{\#} P<0.001$. Significant difference of $\mathrm{RM}+\mathrm{IRR}+\mathrm{CCL}_{4}$ versus corresponding IRR $+\mathrm{CCL}_{4}$ group at ${ }^{\sharp} P<0.001$.

$\square$ Control $\square \mathrm{RM} \square \mathrm{CCL} 4 \mathrm{IIRR}+\mathrm{CCL} 4 \mathrm{QRM}+\mathrm{IRR}+\mathrm{CCL} 4$

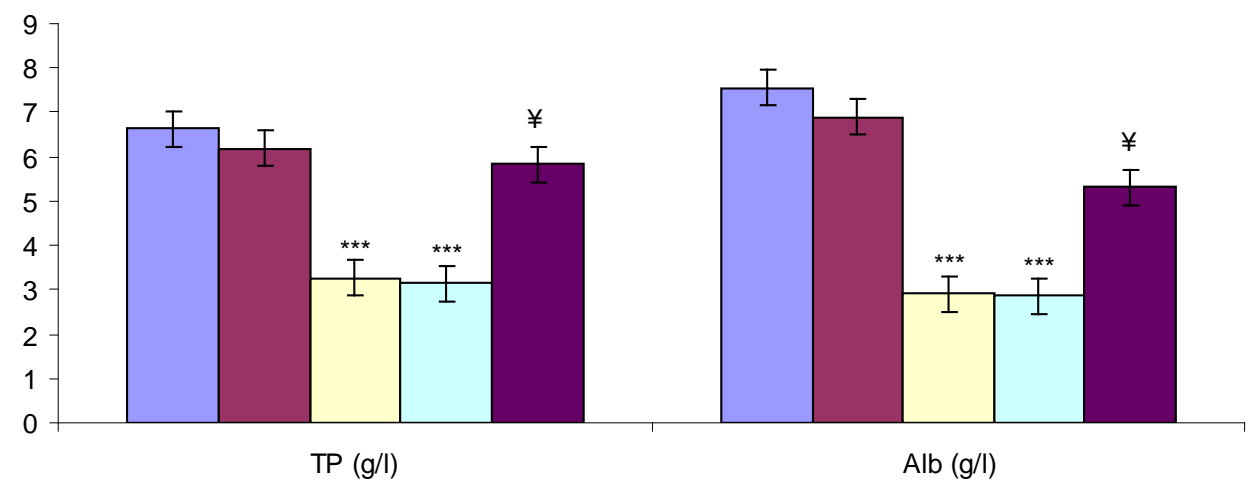

Figure 2. Effect of RM on total protein (TP) and albumin (Alb) in fibrogenic rats. Each value represents the mean $\pm \mathrm{SE}$. $\mathrm{N}=5$ /group. Significant difference versus corresponding control group at ${ }^{* * * *} P<0.001$. Significant difference of $\mathrm{RM}+\mathrm{IRR}+\mathrm{CCl}_{4}$ versus corresponding IRR $+\mathrm{CCL}_{4}$ group at ${ }^{\sharp} P<0.001$.

$\square$ Control $\square$ RM $\square$ CCL4 $\square$ IRR + CCL4 घRM + IRR + CCL4

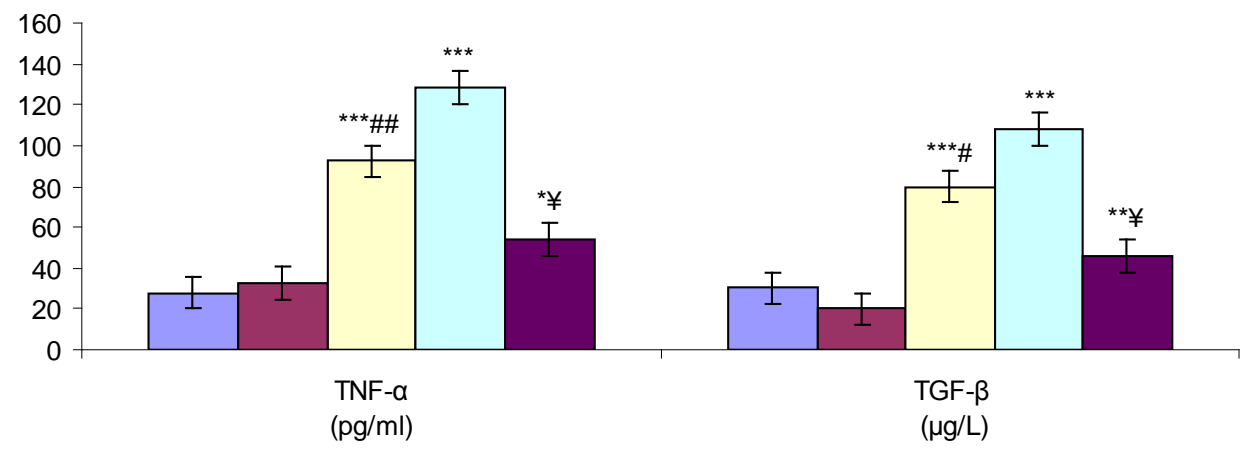

Figure 3. Effect of RM on levels of TNF- $\alpha$ and TGF- $\beta$ in plasma of fibrogenic rats. Each value represents the mean \pm SEM. $N=5$ /group. Significant difference versus corresponding control group at ${ }^{* * *} P<0.001,{ }^{* *} P<0.01$. Significant difference versus corresponding $\mathrm{CCl}_{4}$ at ${ }^{\# \#} P<0.001,{ }^{\#} P<0.01$. Significant difference of $\mathrm{RM}+\mathrm{IRR}+\mathrm{CCl}_{4}$ versus corresponding IRR $+\mathrm{CCl}_{4}$ group at ${ }^{\sharp} P<0.001$. 
口 Control $\square$ RM $\square$ CCL4 $\square \mathrm{IRR}+\mathrm{CCL} 4 \square \mathrm{RM}+\mathrm{IRR}+\mathrm{CCL} 4$

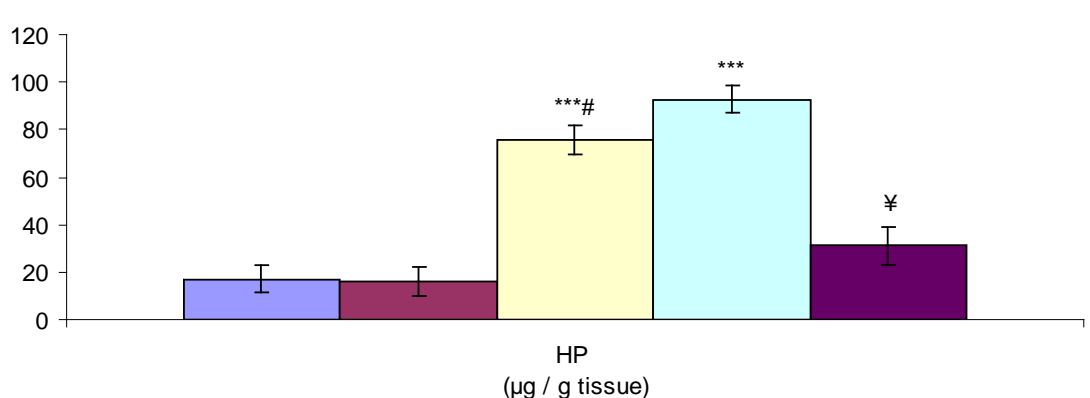

Figure 4. Effect of RM on hydroxyproline (HP) content in liver homogenate of fibrogenic rats. Each value represents the mean \pm SEM. $N=5$ /group. Significant difference versus corresponding control group at ${ }^{* * *} P<0.001,{ }^{* *} P<0.01$. Significant difference versus corresponding $\mathrm{CCl}_{4}$ at ${ }^{\#} P<0.01$. Significant difference of RM + IRR $+\mathrm{CCl}_{4}$ versus corresponding IRR + $\mathrm{CCl}_{4}$ group at ${ }^{¥} \mathrm{P}<0.001$.

$\square$ Control $\square \mathrm{RM} \square \mathrm{CCL} 4 \square \mathrm{IRR}+\mathrm{CCL} 4 \mathrm{QRM}+\mathrm{IRR}+\mathrm{CCL} 4$

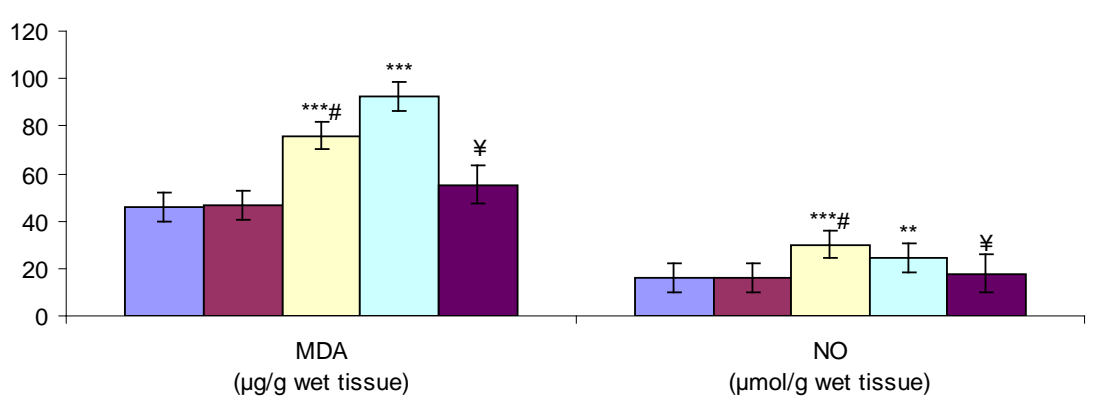

Figure 5. Effect of RM on MDA and NO in liver homogenate of fibrogenic rats. Each value represents the mean $\pm \mathrm{SEM}$. $\mathrm{N}=$ 5/group. Significant difference versus corresponding control group at ${ }^{* * *} P<0.001,{ }^{* *} P<0.01$. Significant difference versus corresponding $\mathrm{CCl}_{4}$ at ${ }^{\sharp} P<0.01$. Significant difference of RM $+\mathrm{IRR}+\mathrm{CCl}_{4}$ versus corresponding IRR $+\mathrm{CCl}_{4}$ group at ${ }^{\sharp} P<$ 0.001 .

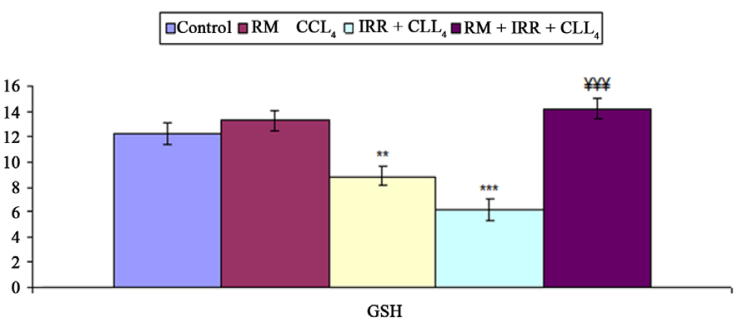

(mg/g wet tissue)
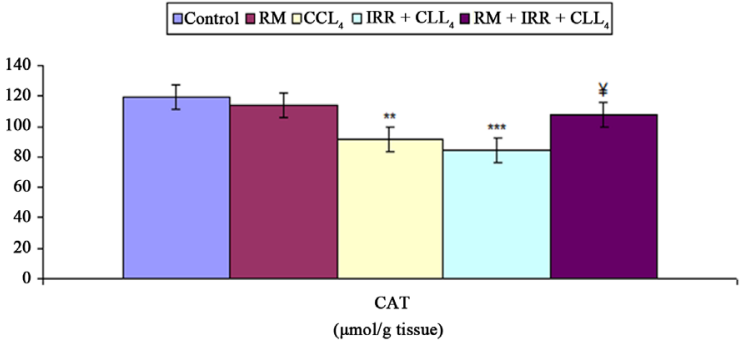

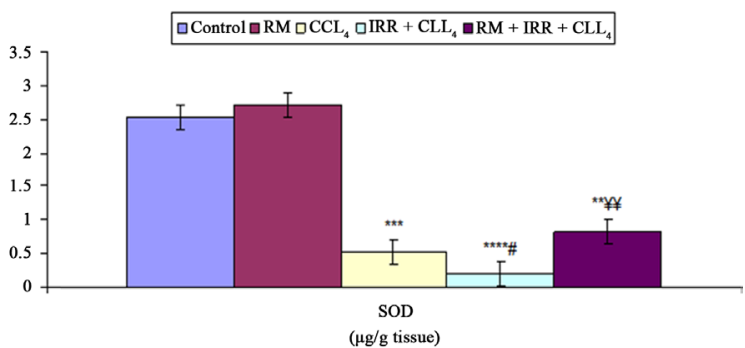

$\square$ Control $\square \mathrm{RM} \square \mathrm{CCL}_{4} \quad \square \mathrm{IRR}+\mathrm{CLL}_{4} \quad \square \mathrm{RM}+\mathrm{IRR}^{2} \mathrm{CLL}_{4}$

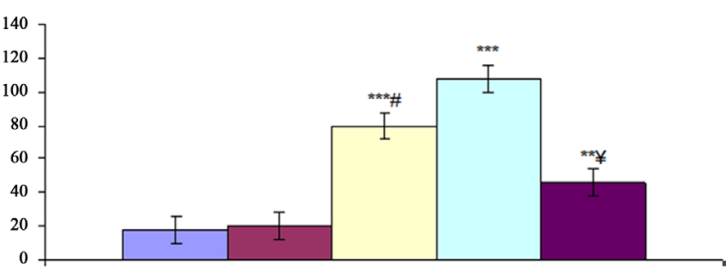

HO-1 Pmol billitubin/mg PT/hr

Figure 6. Effect of RM on GSH content, SOD and CAT activities and HO-1in liver homogenates of fibrogenic rats. Each value represents the mean \pm SEM. Significant difference versus corresponding control group at ${ }^{* * *} P<0.001,{ }^{* *} P<0.01$. Significant difference of IRR $+\mathrm{CCl}_{4}$ versus corresponding $\mathrm{CCl}_{4}$ group at ${ }^{\#} P<0.05$. Significant difference of $\mathrm{RM}+\mathrm{IRR}+\mathrm{CCL}_{4}$ versus corresponding IRR $+\mathrm{CCl}_{4}$ group at ${ }^{\sharp} P<0.05$, ${ }^{\sharp ¥} P<0.01{ }^{\text {¥¥¥ }} P<0.001$. 


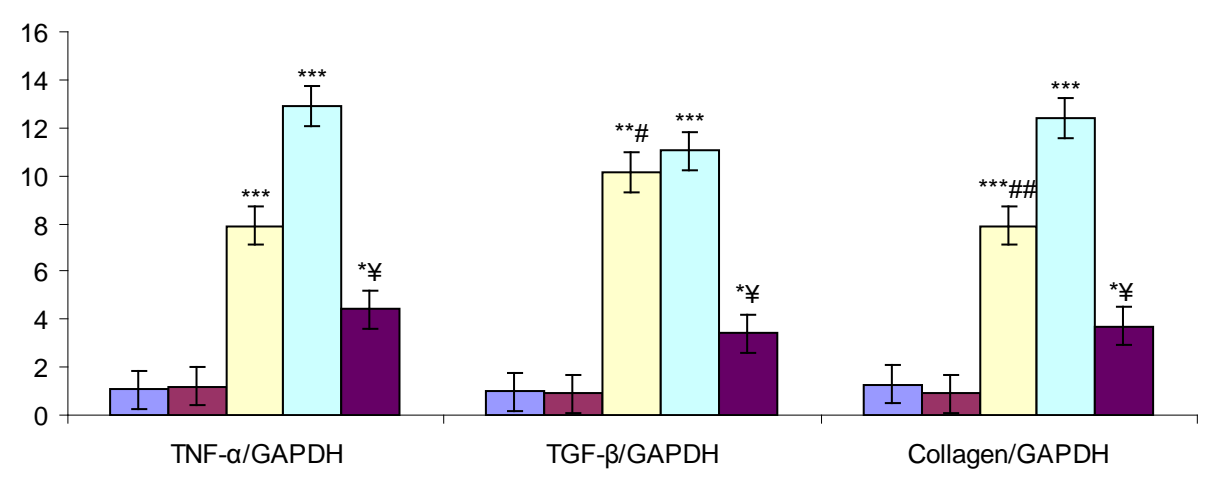

(A)

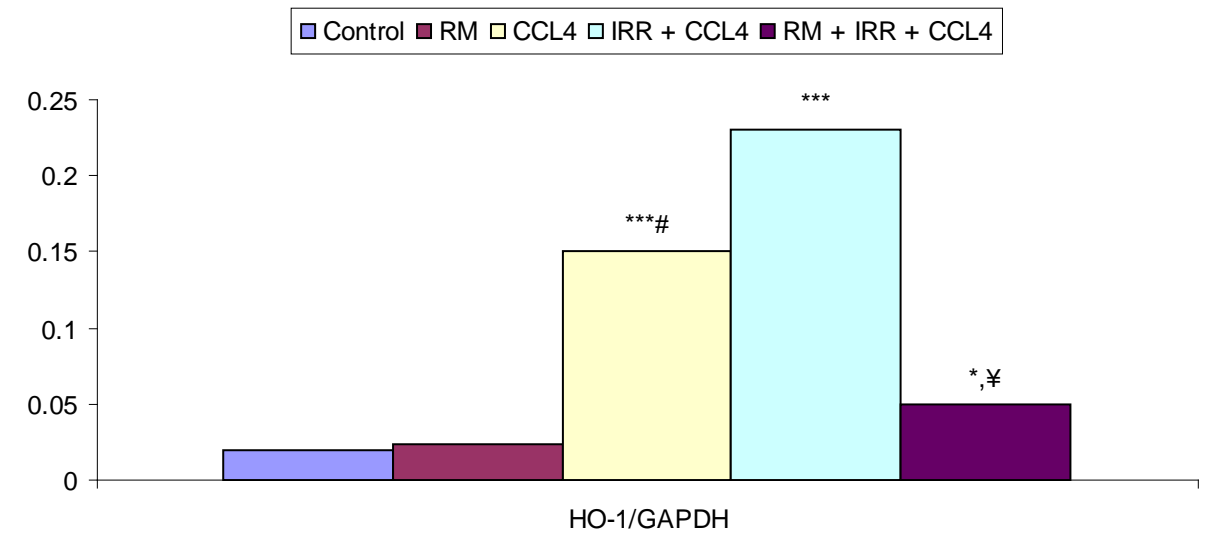

(B)

Figure 7. Effect of RM on (A): mRNA levels of TNF- $\alpha$, TGF- $\beta$ and collagen type-1; (B): HO-1 of fibrotic rats as analyzed by RT-PCR in liver homogenates. Each value represents the mean \pm SEM. Significant difference versus corresponding control group at ${ }^{* * *} P<0.001,{ }^{* *} P<0.01$. Significant difference of $\mathrm{CCl}_{4}$ versus corresponding IRR $+\mathrm{CCl}_{4}$ group at ${ }^{\#} P<0.01,{ }^{\# \#} P<0.001$. Significant difference of RM + IRR $+\mathrm{CCL}_{4}$ versus corresponding IRR $+\mathrm{CCl}_{4}$ group at ${ }^{\sharp} P<0.001$.

However, treatment of fibrotic rats $\left(\mathrm{IRR}+\mathrm{CCl}_{4}\right)$ with $\mathrm{RM}$ was able to significantly $(P<0.001)$ down regulate the mRNA expression of the previous parameters in hepatic tissue when compared to model 2.

\subsection{Histopathological Examination}

Liver of control as well as RM treated rats' revealed normal histological appearance. While examination of different liver sections of $\mathrm{CCl}_{4}$ treated rats revealed massive destruction and alteration in the normal hepatic histology. Centrilobular congestion was evident with disorganization of the hepatic cords and massive fatty change that reached to marked fat steatosis. Necrosis of the hepatocytes as small groups of cells and as single cell necrosis (apoptosis) (Figure 8(A)) was clearly observed in most cases. The portal triads showed inflammatory cells infiltration and marked oval cell hyperplasia Figure 8(B)) that begins to insinuate among the hepatic parenchymal cells with an obvious abundant collagen fibers accumulation (Figure 8(C)). The hepatic normal architecture was unclear with expansion of fibrosis in portal area and peripherally. The expanded fibrosis formed slender fibrous septa that led to conspicuous bridging fibrosis (that demonstrated by Azan stain) (Figure 8(D) and Figure $8(\mathrm{E})$ ) at which the neighboring portal areas were bridged by fibrous septa with beginning of pseudolobulation formation of the hepatic parenchyma. That septa contained inflammatory cells, fat steatotic cells, hyperplastic oval cells and fibroblasts (Figure 8(F)). On the other hand, microscopical examination of livers' sections of IRR $+\mathrm{CCl}_{4}$ treated rats revealed that the exposure of rats to irradiation aggravated the effect of $\mathrm{CCl}_{4}$ in fibrosis induction. The arrangement of the hepatic plate was completely distorted with remarkable fat steatosis. The hepatocytes showed necrosis in fragments with appearance of remnants of degenerated and necrotic 


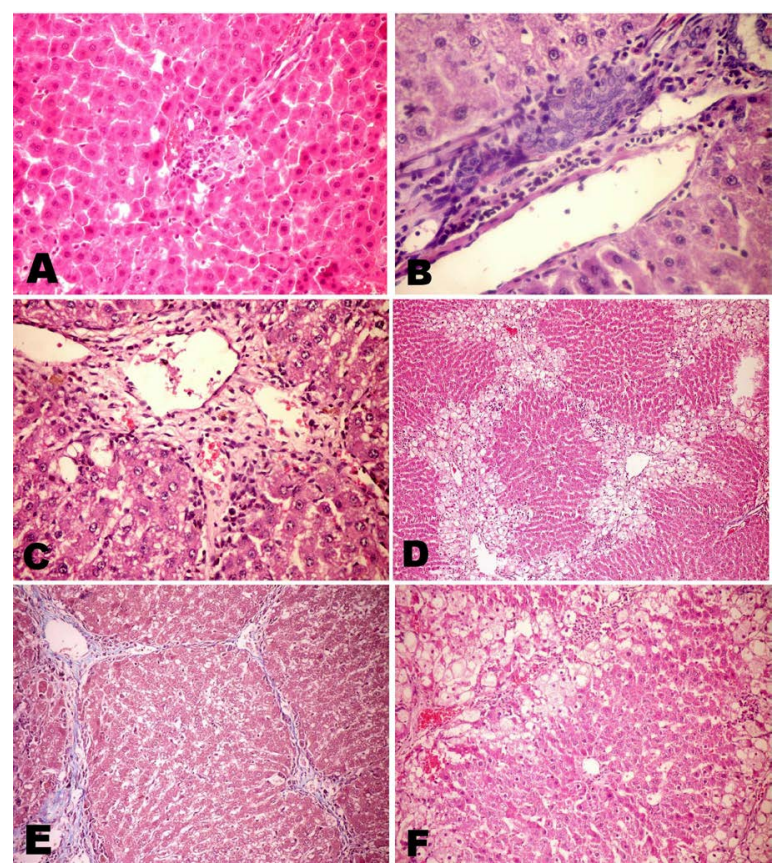

Figure 8. Livers of $\mathrm{CCl}_{4}$ treated rats showing: (A) area of hepatocellular necrosis with multiple apoptotic bodies (arrow); (B) Portal triads with inflammatory cells infiltration and marked oval cell hyperplasia; (C) Abundant collagen fibers accumulation in the portal area and its extension peripherally; (D) Bridging fibrosis between the neighboring portal areas with apparent pseudolobulation formation; (E) Bridging fibrosis (Azan stain); (F) Fibrous septa contained inflammatory cells and fat steatotic cells with hyperplastic oval cells and fibroblasts. (H \& E ×400, 100 and 200).

hepatocytes containing acidophilic hyaline globules (Figure 9(A)).

Extensive collagenous formation was observed that was even showed along the hepatic sinusoids and surrounded the necrotic hepatocytes (Figure 9(B) and Figure 9(C)). Bridging fibrosis was marked and the collagenous septa were much thicker than those of the sole $\mathrm{CCl}_{4}$ treated group causing evident pseudolobuli formation.

It was noticed that $\mathrm{RM}$ co-administration to IRR $+\mathrm{CCl}_{4}$ treated rats could undoubtedly improve the state of steatosis (Figure 9(D)) and increased number of apoptotic bodies as well as apparently suppressed hepatic fibrogenesis. The later was evidenced either by absence of fibrotic septa or in few cases by reducing the thickness of bridging fibrotic septa although collagen fibers accumulation and proliferation in the portal triad was still existed (Figure 9(E)). No obvious pseudolobulation (Figure 9(F)) was observed in most cases.

\subsection{Results of Immunohistochemistry}

Control and RM treated rats showed positive $\alpha$-SMA staining around central vein and portal vein indicating normal expression of myofibroblasts. While, in $\mathrm{CCl}_{4}$ and IRR $+\mathrm{CCl}_{4}$ treated groups, $\alpha$-SMA positive cells were markedly increased in the portal area, around the central vein and along the bridging fibrosis, exhibited the spread of collagen fibers from portal area (Figure 10(A)). Stronger pattern of positivity were observed in IRR + $\mathrm{CCl}_{4}$ treated rats that even extended in the perisinasiodal spaces (Figure 10(B)). However, the expression of $\alpha$-SMA positive cells was decreased in $\mathrm{RM}+\mathrm{IRR}+\mathrm{CCl}_{4}$ treated rats and only observed in the portal area along the accumulated collagen fibers and around the central vein.

\section{Discussion}

In the current study, two models of hepatic fibrosis were generated experimentally in rats along six weeks. It was observed that the exposure to gamma irradiation in the $2^{\text {nd }}$ model could promote and enhance $\mathrm{CCl}_{4}$ induced fibrosis more than the sole use of $\mathrm{CCl}_{4}$ in the $1^{\text {st }}$ model. Moreover, the pathological extent of two models of fibrosis 


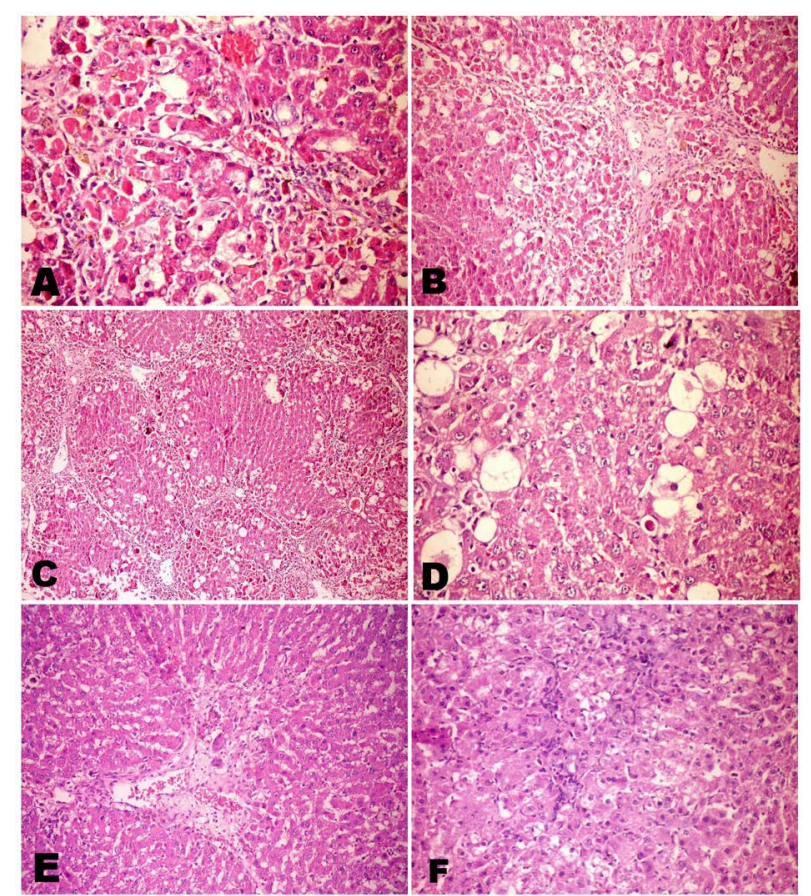

Figure 9. (A), (B), (C) Livers of IRR $+\mathrm{CCl}_{4}$ treated rats showing: (A): Complete distortion of the hepatic plate with necrosis of hepatocytes in fragments; $(B)$ and $(C)$ : Extensive collagenous formation with its interpolation along the hepatic sinusoids and surrounded the necrotic hepatocytes; (D)-(F): Livers of RM + IRR + $\mathrm{CCl}_{4}$ treated rats showing; (D): Improvement of the state of steatosis with marked apoptotic bodies (arrow); (E): Collagen fibers accumulation and proliferation only in the portal triad. (F): Inhibition of hepatic fibrogenesis with no obvious pseudolobulation. (H \& E ×400, 100 and 200).

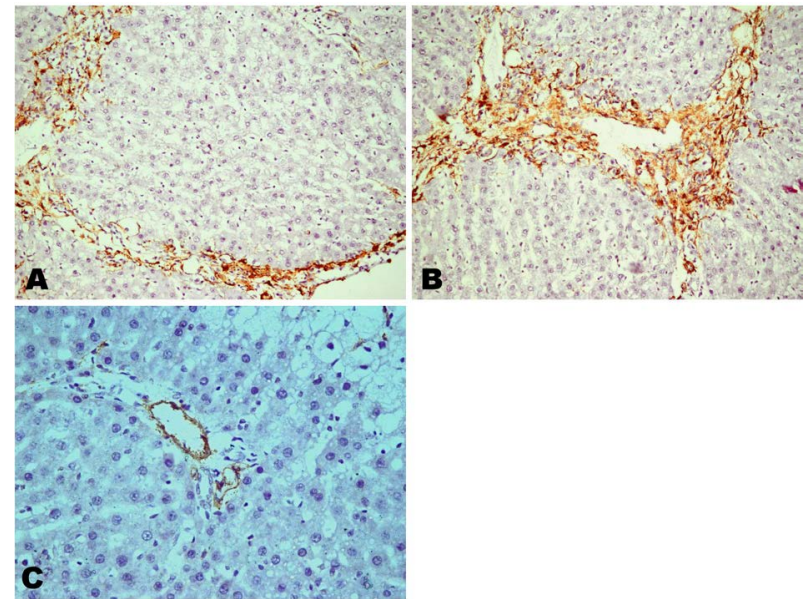

Figure 10. (A) Liver of $\mathrm{CCl}_{4}$ treated rat showing positive $\alpha$-SMA along the fibrous septa; (B) Liver of IRR $+\mathrm{CCl}_{4}$ treated rat showing strong positivity of alpha-SMA in the portal areas and extending along the pseudolobulation; (C) Livers of $\mathrm{RM}+\mathrm{IRR}+\mathrm{CCl}_{4}$ treated rats showing expression of $\alpha$-SMA only in the portal area around portal vein.

and the protective effect of RM against the $2^{\text {nd }}$ model were further evaluated by biochemical and histopathological analysis in this study.

It is well known that: 1) $\mathrm{CCl}_{4}$ is metabolized by cytochrome $\mathrm{P} 450$ in liver into the highly reactive trichloromethyl radicals $\left(\mathrm{CCl}_{3}{ }^{+}\right)$and trichloromethylperoxy radicals $\left(\mathrm{CCl}_{3} \mathrm{O}_{2}{ }^{+}\right)$resulting in initiation of cascade of lipid peroxidation, cell necrosis, steatosis, inflammation; 2) and this compound further promotes progression of hepatic 
[29] [30] which is largely mimics hepatic fibrosis in human diseases [31]. Moreover, the exposure to ionizing radiation can lead to an increase in the generation of ROS leading to lipid peroxidation and oxidative stress [32]. The involvement of ROS and lipid peroxidation in hepatic fibrosis has been reported [33]. Accordingly, in the present work aggravation of fibrosis in the $2^{\text {nd }}$ model was expected due to excessive production of ROS and lipid peroxidation by gamma irradiation [32].

There was a significant decrease in body weight gain of animals of both fibrotic models, which could be contributed to anorexia. Similar reduction in body weight caused by IRR as well as $\mathrm{CCl}_{4}$ has been well documented [34]. Moreover, the increase in liver weight index in the two models follows the same pattern of previous researchers [35] who reported that the increase or decrease in either absolute or index of an organ weight after administration of a chemical or drug could be contributed to the toxic effect of that chemical. The co-treatment of RM to IRR + $\mathrm{CCl}_{4}$ treated rats caused significant restoration in weight gain and significantly reduced the increase in liver weight index, which provided an evidence of the hepato-protective of RM.

The present study showed that the levels of ALT and AST, TP, Alb, TNF- $\alpha$, TGF- $\beta$ were significantly increased in the rats of the two models compared to control. The increased levels of hepatic function markers have been attributed to the liver injury and the release of these enzymes into the blood circulation after the administration of hepatotoxine; such as $\mathrm{CCl}_{4}$ [36]. In addition, the damaged effect of hepatocytes could be due to liberation of large amount of free radicals that induced peroxidative degeneration of membrane lipids and formation of peroxides which probably caused membrane damages [37] and thus cellular alteration.

Total protein and albumin are clinically useful markers of hepatic synthetic function [38]. In agreement with other reports [39], our data indicated that induction of liver fibrosis in rats caused a significant diminution in total protein and albumin which was a further indication of liver damage. However, simultaneous administration of RM with IRR $+\mathrm{CCl}_{4}$ contributes a hepatoprotective mechanism which stimulated protein synthesis and subsequently accelerates the process of regeneration and production of new hepatic cells [40].

Moreover, the observed increase in plasma levels of TNF- $\alpha$ and TGF- $\beta$ in rats of the two models was accompanied with increased their hepatic mRNA expression. Accumulating evidence supports the concept that $\mathrm{CCl}_{4}$ causes lipid peroxidation that leads to hepatocellular membrane damage and followed by the release of proinflammatory mediators, which are thought to potentiate $\mathrm{CCl}_{4}$-induced hepatic damage [41]. Others demonstrated that irradiation induced chronic inflammatory mediators such as rapid activation of TGF- $\beta$ [42] and TNF- $\alpha$ [43] resulted in fibrosis [44]. RM administration to IRR $+\mathrm{CCl}_{4}$ treated rats significantly reduced the elevated levels of the two cytokines in plasma associated with reduction in their mRNA expression in liver tissue. This result is in close relationship with early results which suggested that the suppression that suppression of inflammation and reduced TGF- $\beta$ level have been proposed as a molecular mechanism involved in protection against hepatic fibrosis [45].

Furthermore, our study indicated high HP content in the two established fibrosis models indicated the progression of fibrosis which was assured by the observed up regulation of collagen expression especially in the $2^{\text {nd }}$ model. Hydroxyproline, is an amino acid and a characteristic product of collagen metabolism, its content indicated the total collagen present in liver. In consistent with our findings Fu et al. reported an elevated level of HP in response to $\mathrm{CCl}_{4}$ induced fibrogenesis [46]. This result could be due to activation of the pro-fibrogenic cytokine TGF- $\beta$ and promotion of fibrosis via activation of HSCs [47] and expression of collagen. In addition, gamma irradiation was demonstrated to cause rapid activation of TGF- $\beta$ [42]. However, oral administration of RM could reduce $\mathrm{HP}$ concentration and consequently reduce collagen deposition and suppress the fibrogenic effect induced by $\mathrm{CCl}_{4}$ alone or by combined IRR $+\mathrm{CCl}_{4}$ treatments.

In the current investigation, a significant elevation in MDA and NO levels was recorded associated with significant reduction in GSH concentration, SOD and CAT activities in both fibrotic groups. This is an indication of fibrosis induced oxidative stress in liver. In agreement with our results, early reports demonstrated enhancement of lipid peroxidation after whole body irradiation [48] and $\mathrm{CCl}_{4}$ treatment [49]. The increase in MDA and NO levels could be attributed to high degree of oxidative stress and over production of free radicals and ROS which attack macromolecules such as lipids and proteins initiating lipid peroxidation, thereby, causing depletion of antioxidants.

However, administration of RM to model 2 rats significantly lowered MDA and NO levels, prevented the depletion of GSH and enhanced the activity of antioxidant enzymes as well. This result could be due to the strong free radical scavenger and antioxidant activity of RM which endorsed by the presence of active compounds that are responsible for the hepatoprotective activity as well as the reduction of the free radicals that induce 
oxidative damage to the liver [50].

Regarding, heme oxygenase-1 (HO-1), the rate-limiting enzyme in heme catabolism that is induced by a variety of stimuli including oxidative stress and pro inflammatory cytokines. Our current investigation revealed significant elevation in HO-1 activity and its mRNA expression in hepatic tissue of fibrotic rats. Early reports recorded an elevation in $\mathrm{HO}$ activity and its mRNA expression in hepatic tissue caused by whole body gamma irradiation [51]. Moreover, in a recent study, an abnormal activity of HO-1 after $\mathrm{CCl}_{4}$ treatment has been evidenced [52]. That elevation may be probably due to oxidative stress and inflammation induced by both $\mathrm{CCl}_{4}$ and gamma irradiation. However, concurrent treatment of RM along with IRR $+\mathrm{CCl}_{4}$ brought down the HO- 1 activity and reduced its mRNA expression in hepatic tissue. The protective effect of RM could be due to its strong antioxidant activity.

Our histopathological results revealed marked hepatic tissue alterations as a result of $\mathrm{CCl}_{4}$ and IRR $+\mathrm{CCl}_{4}$ treatments. In addition, the induction of fibrosis models by using composite factors both of IRR and $\mathrm{CCl}_{4} \mathrm{Was}$ succeeded as observed by more clear bridging fibrosis and pseudolobulation of livers of rats exposed to IRR + $\mathrm{CCl}_{4}$ which encouraged the role of IRR in aggravation of hepatic fibrogenesis induced by $\mathrm{CCl}_{4}$. The later effect could be related to the production of large amount of free radicals by both $\mathrm{CCl}_{4}$ and gamma irradiation which by their direct toxic effect could lead to lipid peroxidation and activation of an immune-inflammatory mechanisms that could result in functional and morphological alterations and even cell death [53] [54].

Our results are in agreement with those of [55] [56] who noted that $\mathrm{CCl}_{4}$ administration to mice could induce portal fibrosis and bridging fibrosis as well as regenerating nodules. The observed bridging fibrosis and pseudo lobulation in IRR $+\mathrm{CCl}_{4}$ treated rats were accompanied by increased positivity of $\alpha$-SMA wherever the collagen fibers deposited. That immunopositivity of $\alpha$-SMA indicates activation of HSCs which were responsible for the fibrosis occurrence in $\mathrm{CCl}_{4}$ and IRR $+\mathrm{CCl}_{4}$ treated rats. The later attribution is in agreement with that of [57] who mentioned that; at HSCs activation, the levels of $\alpha$-SMA and desmin increase with decreased GFAP expression due to their transformation into myofibroblast-like cells. Moreover, it has been reported that hepatocytes which undergoing oxidative stress and release of ROS stimulate HSC activation. Prior studies have demonstrated that chronic hepatic fibrosis and inflammation accompanied with Kupffer cell accumulation, HSC activation and collagen deposition [58] [59]. The observed amount of esinophilic hyaline globules of variable sizes in fibrotic lesions of IRR $+\mathrm{CCl}_{4}$ treated rats was correlated with increased collagen deposition and the degree of liver fibrosis. Such bodies or globules could be seen in the hepatocytes in alcoholic and nonalcoholic liver disorders [60]. Those bodies represent abnormal protein aggregates that could be reverted to normal state by molecular chaperones or degradated by proteasomes [61]. However, if reparation or degradation processes fail, abnormal proteins became segregated in the cytoplasm as inclusion bodies. On the other hand, RM administration to IRR $+\mathrm{CCl}_{4}$ treated rats' revealed great ameliorative action of RM on the deleterious effects of both $\mathrm{CCl}_{4}$ and IRR as evidenced by clear absence of bridging fibrosis and pseudolobulation. Such hepato protective and fibrosis-inhibition effects of RM have been recorded [17] [18]. This effect per se may be related to the antioxidant effect of RM' constituents and its scavenging activity of free radicals that reflected on saving the integrity of cellular membranes thus suppressing the inflammatory response and attenuated the fibrosis action.

\section{Conclusion}

In summary, this study provided evidence for experimental model of hepatic fibrosis using gamma irradiation and $\mathrm{CCl}_{4}$. The present study also suggests that $\mathrm{RM}$ aqueous solution showed a considerable hepatoprotective activity against IRR $+\mathrm{CCl}_{4}$ induced hepatic fibrosis and injury in rats. This protective effect could be due to its membrane cellular protection, free radicals scavenging activity, enhancing the endogenous antioxidant system, suppressing the inflammatory responses and attenuation of fibrogenesis. The histopathological study confirmed the biochemical findings.

\section{References}

[1] Hwang, J.M., Tseng, T.H., Tsai, Y.Y., Lee H.J., Chou, F.P., Wang, C.J. and Chu, C.Y. (2005) Protective Effects of Baicalein on Tert-Butyl Hydroperoxide-Induced Hepatic Toxicity in Rat Hepatocytes. Journal of Biomedical Science, 12, 389-397. http://dx.doi.org/10.1007/s11373-005-1572-8

[2] Berasain, C., Castillo, J., Perugorria, M.J., Latasa, M.U., Prieto, J. and Avila, M.A. (2009) Inflammation and Liver Cancer: New Molecular Links. Annals of the New York Academy of Sciences, 1155, 206-221. http://dx.doi.org/10.1111/j.1749-6632.2009.03704.x 
[3] Shao, C.H., Chen, S.L., Dong, T.F., Chai, H., Yu, Y., Deng, L., Wang, Y. and Cheng, F. (2014) Transplantation of Bone Marrow-Derived Mesenchymal Stem Cells after Regional Hepatic Irradiation Ameliorates Thioacetamide-Induced Liver Fibrosis in Rats. The Journal of Surgical Research, 186, 408-416. http://dx.doi.org/10.1016/j.jss.2013.08.016

[4] Pierce, R.A., Glaug, M.R., Greco, R.S., Mackenzie, J.W., Boyd, C.D. and Deak, S.B. (1987) Increased Procollagen mRNA Levels in Carbon Tetrachloride-Induced Liver Fibrosis in Rats. The Journal of Biological Chemistry, 262, 1652-1658.

[5] Manibusan, M.K., Odin, M. and Eastmond, D.A. (2007) Postulated Carbon Tetrachloride Mode of Action: A Review. Journal of Environmental Science and Health, Part C: Environmental Carcinogenesis and Ecotoxicology Reviews, 25, 185-209. http://dx.doi.org/10.1080/10590500701569398

[6] Kamalakkannan, N., Rukkumani, R., Varma, P.S., Viswanathan, P., Rajasekharan, K.N. and Menon, V.P. (2005) Comparative Effects of Curcumin and an Analogue of Curcumin in Carbon Tetrachloride-Induced Hepatotoxicity. Basic and Clinical Pharmacology and Toxicology, 97, 15-22. http://dx.doi.org/10.1111/j.1742-7843.2005.pto_97103.x

[7] Wernke, M.J. and Schell, J.D. (2004) Solvents and Malignancy. Clinics in Occupational and Environmental Medicine, 4, 513-527. http://dx.doi.org/10.1016/j.coem.2004.03.008

[8] Lee, K.S., Buck, M., Houglum, K. and Chojkier, M. (1995) Activation of Hepatic Stellate Cells by TGF Alpha and Collagen Type I Is Mediated by Oxidative Stress through c-myb Expression. Journal of Clinical Investigation, 96, 2461-2468. http://dx.doi.org/10.1172/JCI118304

[9] Wu, J. and Zern, M.A. (2000) Hepatic Stellate Cells: A Target for the Treatment of Liver Fibrosis. Journal of Gastroenterology, 35, 665-672. http://dx.doi.org/10.1007/s005350070045

[10] Nieto, N. (2006) Oxidative-Stress and IL-6 Mediate the Fibrogenic Effects of Rodent Kupffer Cells on Stellate Cells. Hepatology, 44, 1487-1501. http://dx.doi.org/10.1002/hep.21427

[11] Mattila, P., Suonpää, K. and Piironen, V. (2000) Functional Properties of Edible Mushrooms. Nutrition, 16, $694-696$. http://dx.doi.org/10.1016/s0899-9007(00)00341-5

[12] Gao, Y., Gao, H., Chan, E., Tang, W., Xu, A., Yang, H., et al. (2005) Antitumor Activity and Underlying Mechanisms of Ganopoly, the Refined Polysaccharides Extracted from Ganoderma lucidum, in Mice. Immunological Investigations, 34, 171-198. http://dx.doi.org/10.1081/IMM-55813

[13] Ferreira, I.C.F.R., Barros, L. and Abreu, R.M.V. (2009) Antioxidants in Wild Mushrooms. Current Medicinal Chemistry Journal, 16, 1543-1560. http://dx.doi.org/10.2174/092986709787909587

[14] Moro, C., Palacios, I., Lozano, M., DÁrrigo, M., Guillamón, E., Villares, A., Martínez, J.A. and García-Lafuente, A. (2012) Anti-Inflammatory Activity of Methanolic Extracts from Edible Mushrooms in LPS Activated RAW 264.7 Macrophages. Food Chemistry, 130, 350-355. http://dx.doi.org/10.1016/j.foodchem.2011.07.049

[15] Jayakumar, T., Ramesh, E. and Geraldine, P. (2006) Antioxidant Activity of the Oyster Mushroom, Pleurotus ostreatus, on $\mathrm{CCL}_{4}$-Induced Liver Injury in Rats. Food and Chemical Toxicology, 44, 1989-1996.

[16] Lin, J.M., Lin, C.C., Chiu, H.F., Yang, J.J. and Lee, S.G. (1993) Evaluation of the Anti-Inflammatory and Liver-Protective Effects of Anoectochilus formosanus, Ganoderma lucidum and Gynostemma pentaphyllum in Rats. The American Journal of Chinese Medicine, 21, 59-69. http://dx.doi.org/10.1142/S0192415X9300008X

[17] Wang, M.Y., Liu, Q., Che, Q.M. and Lin, Z.B. (2000) Effects of Triterpenoids from Ganderma lucidum (Leyss. Ex Fr.). Karst on Three Different Experimental Liver Injury Models in Mice. Acta Pharmaceutica Sinica B, 35, 326-329.

[18] Park, E.J., Ko, G., Kim, J. and Sohn, D.H. (1997) Antifibrotic Effects of a Polysaccharide Extracted from Ganoderma lucidum, Glycyrrhizin, and Pentoxifylline in Rats with Cirrhosis Induced by Biliary Obstruction. Biological \& Pharmaceutical Bulletin, 20, 417-420. http://dx.doi.org/10.1248/bpb.20.417

[19] Nakamura, T., Sakata, R., Ueno, T., Sata, M. and Ueno, H. (2000) Inhibition of Transforming Growth Factor Beta Prevents Progression of Liver Fibrosis and Enhances Hepatocyte Regeneration in Dimethylnitrosamine Treated Rats. Hepatology, 32, 247-255. http://dx.doi.org/10.1053/jhep.2000.9109

[20] Ohkawa, H., Ohishi, N. and Yagi, K. (1979) Assay for Lipid Peroxides in Animal Tissues by Thiobarbituric Acid Reaction. Analytical Biochemistry, 95, 351-358. http://dx.doi.org/10.1016/0003-2697(79)90738-3

[21] Miranda, K.M., Espey, M.G. and Wink, D.A. (2001) A Rapid Simple Spectrophotometer Method for Simultaneous Detection of Nitrate and Nitrite. Nitric Oxide, 5, 62-71. http://dx.doi.org/10.1006/niox.2000.0319

[22] Beutler, E., Duron, O. and Kelly, B.M. (1963) Improved Method of the Determination of Blood Glutathione. Journal of Laboratory and Clinical Medicine, 61, 882-888.

[23] Minami, M. and Yoshikawa, H.A. (1979) Simplified Assay Method of Superoxide Dismutase Activity for Clinical Use. Clinica Chimica Acta, 92, 337-342. http://dx.doi.org/10.1016/0009-8981(79)90211-0

[24] Johansson, L.H. and Borg, L.A.H. (1988) A Spectrophotometric Method for Determination of Catalase Activity in Small Tissue Sample. Analytical Biochemistry, 174, 331-336. http://dx.doi.org/10.1016/0003-2697(88)90554-4 
[25] Lowry, O.H., Rosebrough, N.J., Farr, A.L. and Randall, R.J. (1951) Protein Measurement with Folin-Phenol Reagent. The Journal of Biological Chemistry, 193, 265-275.

[26] Tenhunen, R., Marver, H.S. and Schmid, R. (1969) Microsomal Heme Oxygenase: Characterization of the Enzyme. The Journal of Biological Chemistry, 244, 6388-6394.

[27] Kenneth, J.L. and Thomas, D.S. (2001) Analysis of Relative Gene Expression Data Using Real-Time Quantitative PCR and 22DDCT. Methods, 25, 402-408. http://dx.doi.org/10.1006/meth.2001.1262

[28] Bancroft, J.D. and Gamble, M. (2008) Theory and Practice of Histological Techniques. 6th Edition, Churchill Livingstone, Elsevier, China.

[29] Fang, H.L., Lai, J.T. and Lin, W.C. (2008) Inhibitory Effect of Olive Oil on Fibrosis Induced by CCL 4 in Rat Liver. Clinical Nutrition, 27, 900-907. http://dx.doi.org/10.1016/j.clnu.2008.08.004

[30] Lee, G., Jeong, W., Jeong, D., Do, S., Kim, T. and Jeong, K. (2005) Diagnostic Evaluation of Carbon TetrachlorideInduced Rat Hepatic Cirrhosis Model. Anticancer Research, 25, 1029-1038.

[31] Pérez Tamayo, R. (1983) Is Cirrhosis of the Liver Experimentally Produced by $\mathrm{CCL}_{4}$ and Adequate Model of Human Cirrhosis? Hepatology, 3, 112-120.

[32] Acharya, M.M., Lan, M.L., Kan, V.H., Patel, N.H., Giedzinski, E., Tseng, B.P. and Limoli, C.L. (2010) Consequences of Ionizing Radiation-Induced Damage in Human Neural Stem Cells. Free Radical Biology and Medicine, 49, 18461855. http://dx.doi.org/10.1016/j.freeradbiomed.2010.08.021

[33] Poli, G. (2000) Pathogenesis of Liver Fibrosis: Role of Oxidative Stress. Molecular Aspects of Medicine, 21, 49-98. http://dx.doi.org/10.1016/S0098-2997(00)00004-2

[34] Moccia, K.D., Olsen, C.H., Mitchell, J.M. and Landauer, M.R. (2010) Evaluation of Hydration and Nutritional Gels as Supportive Care after Total-Body Irradiation in Mice (Mus musculus). Journal of the American Association for Laboratory Animal Science, 49, 323-328.

[35] Orisakwe, O.E., Hussaini, D.C. and Afonne, O.J. (2003) Testicular Effects of Sub-Chronic Administration of Hibiscus sabdariffa Calyx Aqueous Extract in Rats. Reproductive Toxicology, 18, 295-298.

http://dx.doi.org/10.1016/j.reprotox.2003.11.001

[36] Kew, M.C. (2000) Serum Aminotransferase Concentration as Evidence of Hepatocellular Damage. The Lancet, 355, 591-592. http://dx.doi.org/10.1016/S0140-6736(99)00219-6

[37] Kandasamy, C.S., Shimna, T.P., Mohammed, B.E., Arul, R.P., Gopal, V. and Venkatnarayanan, R. (2010) AntiHepatotoxic Activity of Polyherbal Formulation in Carbon Tetrachloride Induced Toxicity in Rats. Research Journal of Pharmaceutical, Biological and Chemical Sciences, 1, 342-346.

[38] Friedman, L.S., Martin, P. and Munoz, S.J. (1996) Liver Function Tests and the Objective Evaluation of the Patient with Liver Disease. In: Zakin, D. and Boyer, T.D., Eds., Hepatology: A Textbook of Liver Disease, 3rd Edition, WB Saunders, Philadelphia.

[39] Navarro, V.J. and Senior, J.R. (2006) Drug-Related Hepatotoxicity. The New England Journal of Medicine, 354, 731739. http://dx.doi.org/10.1056/NEJMra052270

[40] adeusz, J., Teresa, J. and Krzysztof, N. (2001) The Role of Polyprenol in Modulation of Physical Properties of Model Membranes. Current Topics in Biophysics, 25, 33-38.

[41] Kuo, D.H., Kang, W.H., Shieh, P.C., Chen, F.A., Chang, C.D., Tsai, M.L., Cheng, A.C., Ho, C.T. and Pan, M.H. (2010) Protective Effect of Pracparatum mungo Extract on Carbon Tetrachloride-Induced Hepatotoxicity in Rats. Food Chemistry, 123, 1007-1012. http://dx.doi.org/10.1016/j.foodchem.2010.05.052

[42] Travis, E.L., Rachakonda, G., Zhou, X., Korhonen, K., Sekhar, K.R., Biswas, S. and Freeman, M.L. (2011) NRF2 Deficiency Reduces Life Span of Mice Administered Thoracic Irradiation. Free Radical Biology and Medicine, 51, 11751183. http://dx.doi.org/10.1016/j.freeradbiomed.2011.05.038

[43] Zhou, H., Ivanov, V.N., Gillespie, J., Geard, C.R., Amundson, S.A., Brenner, D.J., Yu, Z., Lieberman, H.B. and Hei, T.K. (2005) Mechanism of Radiation-Induced Bystander Effect: Role of the Cyclooxygenase-2 Signaling Pathway. Proceedings of the National Academy of Sciences of the United States of America, 102, 14641-14646. http://dx.doi.org/10.1073/pnas.0505473102

[44] Mattos, M.D., Kimura, E.T., Silva, M.R., Egami, M.I., Segreto, R.A. and Segreto, H.R. (2002) Latent TGFbeta1 Activation in the Lung Irradiated in Vivo. Revista da Associação Médica Brasileira, 48, 329-334.

[45] Chen, W.X., Li, Y.M., Yu, C.H., Cai, W.M., Zheng, M. and Chen, F. (2002) Quantitative Analysis of Transforming Growth Factor Beta 1 mRNA in Patients with Alcoholic Liver Disease. World Journal of Gastroenterology, 8, 379-381.

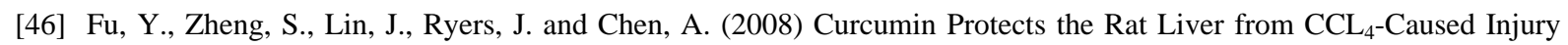
and Fibrogenesis by Attenuating Oxidative Stress and Suppressing Inflammation. Molecular Pharmacology, 73, 399409. http://dx.doi.org/10.1124/mol.107.039818 
[47] Lee, U.E. and Friedman, S.L. (2011) Mechanisms of Hepatic Fibrogenesis. Best Practice \& Research Clinical Gastroenterology, 5, 195-206. http://dx.doi.org/10.1016/j.bpg.2011.02.005

[48] El-Missiry, M.A., Fayed, T.A., El-Sawy, M.R. and El-Sayed, A.A. (2007) Ameliorative Effect of Melatonin against Gamma-Irradiation-Induced Oxidative Stress and Tissue Injury. Ecotoxicology and Environmental Safety, 66, $278-286$. http://dx.doi.org/10.1016/j.ecoenv.2006.03.008

[49] Comporti, M., Arezzini, B., Signorini, C., Sgherri, C., Monaco, B. and Gardi, C. (2005) F2-Isoprostanes Stimulate Collagen Synthesis in Activated Hepatic Stellate Cells: A Link with Liver Fibrosis. Lab Investigation, 85, 1381-1391. http://dx.doi.org/10.1038/labinvest.3700332

[50] Soares, A.A., Babeto de Sá-Nakanishi, A., Bracht, A., Gomes da Costa, S.M., Koehnlein, E.A., Marques de Souza, C.G. and Peralta, R.M. (2013) Hepatoprotective Effects of Mushrooms. Molecules, 18, 7609-7630. http://dx.doi.org/10.3390/molecules18077609

[51] Suzuki, K., Mori, M., Kugawa, F. and Ishihara, H. (2002) Whole-Body X-Irradiation Induces Acute and Transient Expression of Heme Oxygenase-1 in Rat Liver. The Journal of Radiation Research, 43, 205-210. http://dx.doi.org/10.1269/jrr.43.205

[52] Reza, H.M., Sagor, A.T. and Alam, A. (2015) Iron Deposition Causes Oxidative Stress, Inflammation and Fibrosis in Carbon Tetrachloride-Induced Liver Dysfunction in Rats. Bangladesh Journal Pharmacology, 10, 152-159. http://dx.doi.org/10.3329/bjp.v10i1.21711

[53] Brattin, W.J., Glende Jr., E.A. and Recknagel, R.O. (1985) Pathological Mechanisms in Carbon Tetrachloride Hepatotoxicity. Free Radical Biology and Medicine, 1, 27-38. http://dx.doi.org/10.1016/0748-5514(85)90026-1

[54] Geier, A., Dietrich, C.G., Voigt, S., Kim, S.K., Gerloff, T., Kullak-Ublick, G.A., Lorenzen, J., Matern, S. and Gatung, C. (2003) Effects of Proinflammatory Cytokines on Rat Organic Anion Transporters during Toxic Liver Injury and Cholestasis. Hepatology, 38, 345-354. http://dx.doi.org/10.1053/jhep.2003.50317

[55] Ishiki, Y., Ohnishi, H., Muto, Y., Matsumoto, K. and Nakamura, T. (1992) Direct Evidence That Hepatocyte Growth Factor Is a Hepatotrophic Factor for Liver Regeneration and Has a Potent Antihepatitis Effect in Vivo. Hepatology, 16 1227-1235. http://dx.doi.org/10.1016/0270-9139(92)90019-6

[56] Xue, F., Takahara, T., Yata, Y., Kuwabara, Y., Shinno, E., Nonome, K., Minemura, M., Takahara, S., Li, X., Yamato, E. and Watanabe, A. (2003) Hepatocyte Growth Factor Gene Therapy Accelerates Regeneration in Cirrhotic Mouse Livers after Hepatectomy. Gut, 52, 694-700. http://dx.doi.org/10.1136/gut.52.5.694

[57] Campbell, J.S., Hughes, S.D., Gilbertson, D.G., Palmer, T.E., Holdren, M.S., Haran, A.C., Odell, M.M., Bauer, R.L., Ren, H.P., Haugen, H.S., Yeh, M.M. and Fausto, N. (2005) Platelet Derived Growth Factor C Induces Liver Fibrosis, Steatosis, and Hepatocellular Carcinoma. Proceedings of the National Academy of Sciences of the United States of America, 102, 3389-3394. http://dx.doi.org/10.1073/pnas.0409722102

[58] Iredale, J.P. (2007) Models of Liver Fibrosis: Exploring the Dynamic Nature of Inflammation and Repair in a Solid Organ. Journal of Clinical Investigation, 117, 539-548. http://dx.doi.org/10.1172/JCI30542

[59] Jarcuska, P., Janicko, M., Veseliny, E. and Skladany, L. (2010) Circulating Markers of Liver Fibrosis Progression. Clinica Chimica Acta, 411, 1009-1017. http://dx.doi.org/10.1016/j.cca.2010.04.009

[60] Denk, H., Stumptner, C. and Zatloukal, K. (2000) Mallory Bodies Revisited. Journal of Hepatology, 32, 689-702. http://dx.doi.org/10.1016/S0168-8278(00)80233-0

[61] Kopito, R.R. and Sitiam R. (2000) Aggresomes and Russell Bodies. Symptoms of Cellular Indigestion. EMBO Reports, 1, 225-231. http://dx.doi.org/10.1093/embo-reports/kvd052 